\title{
Five gene variants in nonagenarians, centenarians and average individuals
}

\author{
Vana Kolovou ${ }^{1,2}$, Helen Bilianou 3 , Vasiliki Giannakopoulou³, Petros Kalogeropoulos ${ }^{4}$, \\ Constantinos Mihas ${ }^{5}$, Markos Kouris ${ }^{3}$, Dennis V. Cokkinos ${ }^{1}$, Maria Boutsikou ${ }^{1}$, Ioannis Hoursalas ${ }^{1}$, \\ Sophie Mavrogeni ${ }^{1}$, Niki Katsiki ${ }^{6}$, Genovefa Kolovou ${ }^{1}$
}

\author{
${ }^{1}$ Cardiology Department, Onassis Cardiac Surgery Center, Athens, Greece \\ ${ }^{2}$ Molecular Immunology Laboratory, Onassis Cardiac Surgery Center, Athens, Greece \\ ${ }^{3}$ Cardiology Department, Tzanio Hospital, Pireus, Greece \\ ${ }^{4}$ Department of Cardiology, Kostantopoulio Geniko Nosokomio Neas Ionias, Athens, \\ Greece \\ ${ }^{5}$ Internal Medicine Department, Kimi General Hospital, Kimi, Greece \\ ${ }^{6}$ Second Propedeutic Department of Internal Medicine, Medical School, Aristotle \\ University of Thessaloniki, Hippocration Hospital, Thessaloniki, Greece
}

Submitted: 25 November 2016

Accepted: 2 January 2017

Arch Med Sci 2017; 13, 5: 1130-1141

DOI: https://doi.org/10.5114/aoms.2017.68942

Copyright (c) 2017 Termedia \& Banach

\section{Abstract}

Introduction: Genetic factors contribute to the variation of human life span which is believed to be more profound after 85 years of age. The aim of the present study was to evaluate the frequency of 5 gene polymorphisms between nonagenarians, centenarians and average individuals.

Material and methods: Single nucleotide polymorphisms (SNPs) of telomerase reverse transcriptase (TERT; rs2736098), insulin-like growth factor-1 binding protein-3 (IGFBP3; A-202C, rs2857744), fork-head box 03A (FOXO3A; rs 13217795 and rs2764264) factor and adiponectin (ADIPOQ; rs2241766) were evaluated in 405 individuals: $n=256$ nonagenarians and centenarians (study group) and $n=149$ average lifespan individuals (control group aged $18-<80$ years).

Results: The frequency of women was significantly higher in the study group than the control group (64.5 vs. $49.7 \%, p=0.004)$. Genotypic and allele frequencies did not differ between groups according to gender. However, in men, the frequency of TT genotype of FOXO3A; rs2764264 was higher in the study group than the control group ( 45.6 vs. $28.0 \%, p=0.05)$. Overall, the frequency of the $C$ allele of FOXO3A; rs 2764264 was significantly lower in the study group than the control group (3.9 vs. $9.5 \%$, respectively, $p=0.023$ ). Furthermore, in the study group, the $T$ allele was significantly more frequent in the nonagenarians $(n=239)$ than the centenarians $(n=17)$ in both FOXO3A; rs 13217795 and rs2764264 (64.4 vs. $44.1 \%$, $p=0.018$ and 69.7 vs. $50.0 \%, p=0.017$, respectively).

Conclusions: According to survival status, there is differentiation in the prevalence of both studied FOXO3A gene polymorphisms. The study group had half of the $C$ alleles compared with the control group and centenarians less frequently had the $T$ allele of both FOXO3A gene polymorphisms compared with nonagenarians. No difference was found between groups according to TERT, IGFBP3 and ADIPOQ gene polymorphisms. It seems that some polymorphisms may be significant in prolonging our lifespan. Nevertheless, confirmation in additional study populations is needed.

Key words: nonagenarians, centenarians, single nucleotide polymorphisms, TERT, IGFBP3, FOXO3A, ADIPOQ.

\section{Corresponding author:} Genovefa D. Kolovou MD, PhD, FESC, SFASA, FRSPH Cardiology Department Lipid Disorders Clinic

Onassis Cardiac

Surgery Center

356 Sygrou Ave 17674 Athens, Greece Phone: +30 2109493520 Fax: +30 2109493336 E-mail: genovefa@kolovou. com 


\section{Introduction}

Long lasting living has been a desire and a target for human beings [1]. During the last 2 decades, several research groups have been vigorously evaluating various single nucleotide polymorphisms (SNPS) involved in human ageing or exceptional longevity [2-4]. Consequently, many studies evaluating the frequency of particular gene polymorphisms in ageing have already been published, with inconsistent results. The main reasons for these conflicting results are the differences in nationality, gender and environmental status of the evaluated cohorts. Furthermore, it is possible that, apart from environmental factors, every nation may have favorable and non-favorable combinations of gene polymorphisms, leading to longer or shorter lifespan. Moreover, it is believed that genetic influence is more profound after the age of 85 years [2].

To inhibit the loss of coding sequences and suppress the chromosomal reorganizations, linear chromosomes are capped by repetitive nucleoprotein structures, named telomeres. Every cell splitting results in a gradual reduction of telomere length that, below a certain shortening, evokes genome instability, senescence and apoptosis. Telomerase, a ribonucleic protein that consists of a telomere reverse transcriptase (TERT, catalytic subunit) and a telomere RNA component, is the main regulator of telomere length $[4,5]$. The TERT gene encodes the catalytic subunit of telomerase. In the present study, in line with a previous one [3], we investigated gene variants that could explain the extended lifespan of nonagenarians and centenarians compared with middle-aged individuals in the Greek population. In this context, we evaluated the TERT gene polymorphism rs2736098, located on chromosome 5 at position NM_001193376.1: c.915G>A, that appears to associate with cancer diseases (one of the major causes of shortened lifespan).

Insulin-like growth factor-1 (IGF-1) was negatively correlated with age [6]. Circulating insulin-like growth factor-1 binding protein-3 (IGFBP-3) is bound to about $90 \%$ of the circulating IGF-1 that exerts mitogenic and metabolic activities in the regulation of growth, survival and cell differentiation [7]. IGFBP3 (A-202C, rs2854744) gene polymorphism, located on chromosome 7 at position NM 000598.4: C.-336C>A, was found to be significantly associated with circulating IGFBP-3 levels. There is some evidence that the alleles associated with higher circulating IGFBP-3 levels are also associated with higher risk of early stage of cancers [8].

Genetic variations in transcription factor Forkhead box O3A (FOXO3A) have been associated with human longevity in nations such as the Japanese, Chinese, Italian and German [9-12]. FOXO3A forms part of the IGF-1 signaling pathway. In the present study, we evaluated two SNPs of the

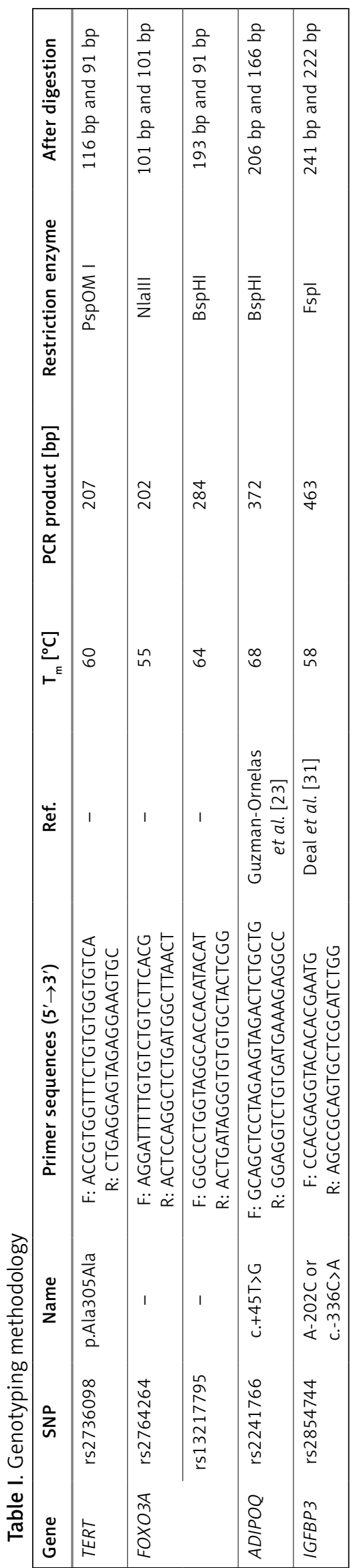


V. Kolovou, H. Bilianou, V. Giannakopoulou, P. Kalogeropoulos, C. Mihas, M. Kouris, D.V. Cokkinos, M. Boutsikou, I. Hoursalas, S. Mavrogeni, N. Katsiki, G. Kolovou

FOXO3A gene (rs13217795 located on chromosome 6 at position NM_01455.3: c.622-10560C >T and rs2764264 located on chromosome 6 at position NM_001455.3: c.622-50197C>T). The IGF-1 pathway highly interacts with the 553 pathway, a nuclear protein involved in several signaling pathways, including DNA damage recognition, cell cycle control and meiotic recombination (important components involved in longevity) [13].

Adiponectin, an adipose tissue-derived peptide, is a determinant of insulin sensitivity that exerts anti-inflammatory and anti-atherogenic effects. Decreased plasma adiponectin levels are associated with type 2 diabetes mellitus and atherosclerosis (both diseases can shorten the lifespan). The adiponectin-encoding gene (ADIPOQ) is located on chromosome 3 and the SNP which we evaluated $(A D I P O Q+45 T>G)$ is at position NM_004797.3: c. $45 \mathrm{~T}>\mathrm{G}[14]$.

We made the hypothesis that gene polymorphisms involved either in cell instability, senescence, and apoptosis or determining the risk of diseases development leading to lifespan shortening (cancer, diabetes mellitus, coronary heart disease (CHD)) will present with different frequencies according to age.

The aim of the present study was to evaluate whether there is any difference in the frequency of common gene polymorphisms (i.e. TERT, IGFBP3, FOXO3A and ADIPOQ) between nonagenarians and centenarians (study group) and middle-aged individuals (control group).

Table II. Genotype frequencies between the study group and the control group

\begin{tabular}{|c|c|c|c|c|c|c|c|}
\hline \multirow[t]{2}{*}{ Variable } & \multicolumn{2}{|c|}{ All } & \multicolumn{2}{|c|}{ Control group } & \multicolumn{2}{|c|}{ Study group } & \multirow[t]{2}{*}{$P$-value } \\
\hline & $N$ & $N \%$ & $N$ & $N \%$ & $N$ & $N \%$ & \\
\hline \multicolumn{8}{|l|}{ Gender: } \\
\hline Male & 166 & 41.0 & 75 & 50.3 & 91 & 35.5 & 0.004 \\
\hline Female & 239 & 59.0 & 74 & 49.7 & 165 & 64.5 & \\
\hline \multicolumn{8}{|c|}{ Genotypes: } \\
\hline \multicolumn{8}{|c|}{ TERT rs2736098* } \\
\hline AA & 31 & 8.2 & 8 & 6.3 & 23 & 8.9 & 0.685 \\
\hline$A G$ & 154 & 40.4 & 52 & 40.6 & 103 & 40.2 & \\
\hline GG & 196 & 51.4 & 68 & 53.1 & 130 & 50.5 & \\
\hline \multicolumn{8}{|c|}{ IGFBP3 rs2854744*: } \\
\hline AA & 106 & 28.4 & 29 & 24.4 & 77 & 30.3 & 0.392 \\
\hline$A C$ & 188 & 50.4 & 61 & 51.3 & 127 & 50.0 & \\
\hline $\mathrm{CC}$ & 79 & 21.2 & 29 & 24.4 & 50 & 19.7 & \\
\hline \multicolumn{8}{|c|}{ FОХОЗА rs13217795: } \\
\hline $\mathrm{CC}$ & 55 & 13.6 & 22 & 14.9 & 33 & 12.9 & 0.837 \\
\hline $\mathrm{CT}$ & 191 & 47.3 & 68 & 45.9 & 123 & 48.0 & \\
\hline $\mathrm{TT}$ & 158 & 39.1 & 58 & 39.2 & 100 & 39.1 & \\
\hline \multicolumn{8}{|c|}{ FOXO3A rs2764264: } \\
\hline TT & 158 & 39.1 & 54 & 36.5 & 104 & 40.6 & 0.070 \\
\hline $\mathrm{TC}$ & 222 & 55.0 & 80 & 54.1 & 142 & 55.5 & \\
\hline $\mathrm{CC}$ & 24 & 5.9 & 14 & 9.5 & 10 & 3.9 & \\
\hline \multicolumn{8}{|c|}{ ADIPOQ rs2241766: } \\
\hline $\mathrm{TT}$ & 276 & 68.7 & 100 & 67.6 & 176 & 69.0 & 0.124 \\
\hline TG & 115 & 28.6 & 47 & 31.7 & 70 & 27.1 & \\
\hline GG & 11 & 2.7 & 1 & 0.7 & 10 & 3.9 & \\
\hline
\end{tabular}

*20 genotype analyses were missing in the control group. 


\section{Material and methods}

The present study was designed and performed in agreement with the recommendations for the human genotype-phenotype association studies published by the National Cancer InstituteNational Human Genome Research Institute (NCl-NHGRI) Working Group on Replication in Association Studies [15] indicating the time period and location of subject recruitment, success rate for DNA acquisition, internal control samples (from the same DNA) and sample tracking methods.

The study protocol was approved by the Institutional Ethics Committee (Onassis Cardiac Surgery Center, Athens, Greece) and was in accordance with the Declaration of Helsinki for Human Research of 1974 (last modified in 2000) [16]. All study participants were of Caucasian origin and descent for $\geq 3$ generations.

Control group ( $n=149)$. The inclusion criteria were: 1 . age $18-<80$ years, and 2. no personal history of CHD, diabetes mellitus, thyroid or liver disease, high alcohol consumption, professional athleticism and any chronic disease.

Study group with nonagenarians and centenarians $(n=256)$. The inclusion criteria were age 90-99 years in nonagenarians and > 99 years in centenarians. No other inclusion or exclusion criteria were applied.

\section{Genotyping}

Genotyping was performed specifically for research purposes. Extraction of genomic DNA was

Table III. Genotype frequencies in men

\begin{tabular}{|c|c|c|c|c|c|}
\hline \multirow[t]{2}{*}{ Variable } & \multicolumn{2}{|c|}{ Control group } & \multicolumn{2}{|c|}{ Study group } & \multirow[t]{2}{*}{$P$-value } \\
\hline & $N$ & $N \%$ & $N$ & $N \%$ & \\
\hline \multicolumn{6}{|l|}{ Gender: } \\
\hline Male & 75 & 100.0 & 91 & 100.0 & \\
\hline Female & 0 & 0.0 & 0 & 0.0 & \\
\hline \multicolumn{6}{|c|}{ Genotypes: } \\
\hline \multicolumn{6}{|c|}{ TERT rs2736098: } \\
\hline $\mathrm{AA}$ & 7 & 11.1 & 8 & 8.8 & 0.890 \\
\hline GA & 26 & 41.3 & 38 & 41.8 & \\
\hline GG & 30 & 47.6 & 45 & 49.5 & \\
\hline \multicolumn{6}{|c|}{ IGFBP3 rs2854744: } \\
\hline $\mathrm{AA}$ & 16 & 27.1 & 27 & 30.7 & 0.785 \\
\hline $\mathrm{AC}$ & 29 & 49.2 & 44 & 50.0 & \\
\hline $\mathrm{CC}$ & 14 & 23.7 & 17 & 19.3 & \\
\hline \multicolumn{6}{|c|}{ FOXO3A rs13217795: } \\
\hline $\mathrm{CC}$ & 12 & 16.2 & 14 & 15.6 & 0.413 \\
\hline $\mathrm{CT}$ & 38 & 51.4 & 38 & 42.2 & \\
\hline $\mathrm{TT}$ & 24 & 32.4 & 38 & 42.2 & \\
\hline \multicolumn{6}{|c|}{ FOXO3A rs2764264: } \\
\hline TT & 21 & 28.0 & 41 & 45.6 & 0.050 \\
\hline $\mathrm{CT}$ & 47 & 62.7 & 45 & 50.0 & \\
\hline $\mathrm{CC}$ & 7 & 9.3 & 4 & 4.4 & \\
\hline \multicolumn{6}{|c|}{ ADIPOQ rs2241766: } \\
\hline $\mathrm{TT}$ & 46 & 61.3 & 61 & 67.8 & 0.291 \\
\hline TG & 28 & 37.3 & 25 & 27.8 & \\
\hline GG & 1 & 1.3 & 4 & 4.4 & \\
\hline
\end{tabular}


V. Kolovou, H. Bilianou, V. Giannakopoulou, P. Kalogeropoulos, C. Mihas, M. Kouris, D.V. Cokkinos, M. Boutsikou, I. Hoursalas, S. Mavrogeni, N. Katsiki, G. Kolovou

performed from leukocytes separated from whole blood using a standard method with the FlexiGene DNA kit (Qiagen).

The study variants were detected using polymerase chain reaction (PCR) and restricted fragment length polymorphism analysis (RFLPs). The PCR was performed using KAPA TaqDNA polymerase (KAPA Biosystems). The oligonucleotide primers, the PCR conditions and the restriction enzymes for each SNP are listed in Table I. All samples were subjected to electrophoresis on an agarose gel $3 \%$ and visualized with ethidium bromide.

The RFLP results were validated by: 1) around $20 \%$ of all samples were repeated to confirm findings of the PCR-RFLP method and 2) randomly selected PCR-RFLP results were confirmed by direct automated sequencing of PCR products for each polymorphism using the BigDye terminator chemistry kit ( $A B I, U S A)$ and 3500 genetic analyzer ( $A B I$, USA). The concordance between repeated samples, sequencing and our results was $100 \%$.

\section{Statistical analysis}

All categorical variables are described as absolute $(N)$ and relative (\%) frequencies. Potential associations between the study variables were tested using Pearson's $\chi^{2}$ test or Fisher's exact test, when appropriate. All tests were two-sided and were considered significant if the $p$-value was $<0.05$. Data were analyzed using IBM SPSS statistical software version 22.0 for Windows (IBM Corporation, NY, USA).

Table IV. Genotype frequencies in women

\begin{tabular}{|c|c|c|c|c|c|}
\hline \multirow[t]{2}{*}{ Variable } & \multicolumn{2}{|c|}{ Control group } & \multicolumn{2}{|c|}{ Study group } & \multirow[t]{2}{*}{$P$-value } \\
\hline & $N$ & $N \%$ & $N$ & $N \%$ & \\
\hline \multicolumn{6}{|l|}{ Gender: } \\
\hline Male & 0 & 0.0 & 0 & 0.0 & \\
\hline Female & 74 & 100.0 & 165 & 100.0 & \\
\hline \multicolumn{6}{|c|}{ Genotypes: } \\
\hline \multicolumn{6}{|c|}{ TERT rs2736098: } \\
\hline AA & 1 & 1.6 & 15 & 9.1 & 0.132 \\
\hline GA & 24 & 39.3 & 66 & 40.0 & \\
\hline GG & 36 & 59.0 & 84 & 50.9 & \\
\hline \multicolumn{6}{|c|}{ IGFBP3 rs2854744: } \\
\hline AA & 13 & 21.7 & 50 & 30.3 & 0.384 \\
\hline$A C$ & 32 & 53.3 & 83 & 50.3 & \\
\hline $\mathrm{CC}$ & 15 & 25.0 & 32 & 19.4 & \\
\hline \multicolumn{6}{|c|}{ FOXO3A rs13217795: } \\
\hline $\mathrm{CC}$ & 10 & 13.5 & 19 & 11.5 & 0.331 \\
\hline $\mathrm{CT}$ & 30 & 40.5 & 84 & 50.9 & \\
\hline TT & 34 & 45.9 & 62 & 37.6 & \\
\hline \multicolumn{6}{|c|}{ FOXO3A rs2764264: } \\
\hline TT & 33 & 45.2 & 63 & 38.2 & 0.065 \\
\hline $\mathrm{CT}$ & 33 & 45.2 & 96 & 58.2 & \\
\hline $\mathrm{CC}$ & 7 & 9.6 & 6 & 3.6 & \\
\hline \multicolumn{6}{|c|}{ ADIPOQ rs2241766: } \\
\hline TT & 54 & 75.0 & 114 & 69.5 & 0.283 \\
\hline TG & 18 & 25.0 & 44 & 26.8 & \\
\hline GG & 0 & 0.0 & 6 & 3.7 & \\
\hline
\end{tabular}




\section{Results}

The age of the study group ranged between 90 and 113 years (median \pm interquartile range (IQR): $93 \pm 4$ years). Overall, 17 individuals were centenarians (from 100 to 113 years, $101 \pm 5$ years). The corresponding age of the control group was $56 \pm 27$ years, ranging from 18 to 80 years. The frequency of women was significantly higher in the study group than the control group (64.5 vs. $49.7 \%, p=0.004$ ) (Table II).

\section{Genetic gender difference}

Genotypic (Tables III-VI) and allele frequencies (not shown) did not differ by gender in either of the 2 groups. However, in men, the frequency of TT genotype of FOXO3A; rs2764264 was higher in the study group than the control group (45.6 vs. 28.0\%, $p=0.050$ ) (Table III).

\section{Gene distribution in the study group and control group}

No significant difference was found in the distribution of all genotypes between the 2 groups (Table II). When the evaluation was referred to the alleles, the relative frequency of the $C$ allele (FOXO3A, rs2764264) was significantly lower in the study group than the control group (3.9 vs. 9.5\%, $p=0.023$ ) (Table VII).

\section{Nonagenarians and centenarians}

Although there were significant differences in the distribution of genotypes between nonagenarians and centenarians in FOXO3A rs13217795 and FOXO3A rs2764264, the small number of observations among genotypes cannot lead to certain conclusions (Table VIII). However, when testing by allele, the $T$ allele was significantly more

Table V. Genotype frequencies in the control group according to gender

\begin{tabular}{|c|c|c|c|c|c|}
\hline \multirow[t]{4}{*}{ Genotypes } & \multicolumn{4}{|c|}{ Control group } & \multirow[t]{4}{*}{$P$-value } \\
\hline & \multicolumn{4}{|c|}{ Gender } & \\
\hline & \multicolumn{2}{|c|}{ Male } & \multicolumn{2}{|c|}{ Female } & \\
\hline & $N$ & $N \%$ & $N$ & $N \%$ & \\
\hline \multicolumn{6}{|c|}{ TERT rs2736098: } \\
\hline $\mathrm{AA}$ & 7 & 11.1 & 1 & 1.6 & 0.085 \\
\hline GA & 26 & 41.3 & 24 & 39.3 & \\
\hline GG & 30 & 47.6 & 36 & 59.0 & \\
\hline \multicolumn{6}{|c|}{ IGFBP3 rs2854744: } \\
\hline AA & 16 & 27.1 & 13 & 21.7 & 0.785 \\
\hline$A C$ & 29 & 49.2 & 32 & 53.3 & \\
\hline $\mathrm{CC}$ & 14 & 23.7 & 15 & 25.0 & \\
\hline \multicolumn{6}{|c|}{ FOXO3A rs13217795: } \\
\hline $\mathrm{CC}$ & 12 & 16.2 & 10 & 13.5 & 0.241 \\
\hline $\mathrm{CT}$ & 38 & 51.4 & 30 & 40.5 & \\
\hline TT & 24 & 32.4 & 34 & 45.9 & \\
\hline \multicolumn{6}{|c|}{ FOXO3A rs2764264: } \\
\hline TT & 21 & 28.0 & 33 & 45.2 & 0.078 \\
\hline $\mathrm{CT}$ & 47 & 62.7 & 33 & 45.2 & \\
\hline $\mathrm{CC}$ & 7 & 9.3 & 7 & 9.6 & \\
\hline \multicolumn{6}{|c|}{ ADIPOQ rs2241766: } \\
\hline TT & 46 & 61.3 & 54 & 75.0 & 0.111 \\
\hline TG & 28 & 37.3 & 18 & 25.0 & \\
\hline GG & 1 & 1.3 & 0 & 0.0 & \\
\hline
\end{tabular}


V. Kolovou, H. Bilianou, V. Giannakopoulou, P. Kalogeropoulos, C. Mihas, M. Kouris, D.V. Cokkinos, M. Boutsikou, I. Hoursalas, S. Mavrogeni, N. Katsiki, G. Kolovou

frequent in the nonagenarians than the centenarians in both FOXO3A rs13217795 and FOXO3A rs2764264 (64.4 vs. $44.1 \%, p=0.018,69.7$ vs. $50.0 \%, p=0.017$, respectively; Table IX).

\section{Discussion}

We studied 5 SNPs in 4 candidate genes in pathways related to lipoprotein and glucose metabolism as well as to telomere length, given the fact that both pathways are closely related to ageing/longevity. We found that the frequency of the $C$ allele of FOXO3A; rs2764264 was lower in the study group than in the control group and that the $T$ allele was more frequent in nonagenarians compared with centenarians of both FOXO3A gene variants (rs13217795 and rs2764264). Furthermore, genotypic and allele frequencies did not differ between the 2 groups according to gender, although, in men, the frequency of TT genotype of FOXO3A; rs2764264 was higher in the study group than the control group.

Therefore, the present study demonstrated that, among the 4 candidate genes, only one gene (i.e. FOXO3A) may have a potential influence on human longevity.

Various studies have reported significant inter-individual variation in telomere length and telomerase activity in healthy individuals of the same age $[17,18]$. It has been observed that individuals with shorter telomeres are at higher risk of diseases that shorten lifespan such as cancers (e.g. lung cancer) [19]. With regard to age, we found no differences in the frequency of TERT gene polymorphism. In accordance with our finding, Liu et al. also reported no influence of TERT gene polymorphism on human lifespan in Han Chinese peri-centenarians [20]. Bressler et al. [18] evaluated the association between six TERT

Table VI. Genotype frequencies in the study group according to gender

\begin{tabular}{|c|c|c|c|c|c|}
\hline \multirow[t]{4}{*}{ Genotypes } & \multicolumn{4}{|c|}{ Study group } & \multirow[t]{4}{*}{$P$-value } \\
\hline & \multicolumn{4}{|c|}{ Gender } & \\
\hline & \multicolumn{2}{|c|}{ Male } & \multicolumn{2}{|c|}{ Female } & \\
\hline & $N$ & $N \%$ & $N$ & $N \%$ & \\
\hline \multicolumn{6}{|c|}{ TERT rs2736098: } \\
\hline AA & 8 & 8.8 & 15 & 9.1 & 0.963 \\
\hline GA & 38 & 41.8 & 66 & 40.0 & \\
\hline GG & 45 & 49.5 & 84 & 50.9 & \\
\hline \multicolumn{6}{|c|}{ IGFBP3 rs2854744: } \\
\hline AA & 27 & 30.7 & 50 & 30.3 & 0.998 \\
\hline $\mathrm{AC}$ & 44 & 50.0 & 83 & 50.3 & \\
\hline $\mathrm{CC}$ & 17 & 19.3 & 32 & 19.4 & \\
\hline \multicolumn{6}{|c|}{ FOXO3A rs13217795: } \\
\hline $\mathrm{CC}$ & 14 & 15.6 & 19 & 11.5 & 0.373 \\
\hline $\mathrm{CT}$ & 38 & 42.2 & 84 & 50.9 & \\
\hline $\mathrm{TT}$ & 38 & 42.2 & 62 & 37.6 & \\
\hline \multicolumn{6}{|c|}{ FOXО3A rs2764264: } \\
\hline $\mathrm{TT}$ & 41 & 45.6 & 63 & 38.2 & 0.454 \\
\hline $\mathrm{CT}$ & 45 & 50.0 & 96 & 58.2 & \\
\hline $\mathrm{CC}$ & 4 & 4.4 & 6 & 3.6 & \\
\hline \multicolumn{6}{|c|}{ ADIPOQ rs2241766: } \\
\hline $\mathrm{TT}$ & 61 & 67.8 & 114 & 69.5 & 0.934 \\
\hline TG & 25 & 27.8 & 44 & 26.8 & \\
\hline GG & 4 & 4.4 & 6 & 3.7 & \\
\hline
\end{tabular}


Table VII. Allele frequencies among the 2 studied groups (in both genders)

\begin{tabular}{|c|c|c|c|c|c|}
\hline \multirow[t]{2}{*}{ Alleles } & \multicolumn{2}{|c|}{ Control group } & \multicolumn{3}{|c|}{ Study group } \\
\hline & $N$ & $N \%$ & $N$ & $N \%$ & $P$-value \\
\hline \multicolumn{6}{|c|}{ TERT rs2736095: } \\
\hline A & 58 & 46.8 & 127 & 49.4 & 0.629 \\
\hline G & 66 & 53.2 & 130 & 50.6 & \\
\hline \multicolumn{6}{|c|}{ IGFBP3 rs2854744: } \\
\hline A & 90 & 75.6 & 204 & 80.3 & 0.302 \\
\hline C & 29 & 24.4 & 50 & 19.7 & \\
\hline \multicolumn{6}{|c|}{ FOXO3A rs13217795: } \\
\hline C & 90 & 60.8 & 156 & 60.9 & 0.980 \\
\hline $\mathrm{T}$ & 58 & 39.2 & 100 & 39.1 & \\
\hline \multicolumn{6}{|c|}{ FOXO3A rs2764264: } \\
\hline T & 134 & 90.5 & 246 & 96.1 & 0.023 \\
\hline C & 14 & 9.5 & 10 & 3.9 & \\
\hline \multicolumn{6}{|c|}{ ADIPOQ rs2241766: } \\
\hline T & 146 & 99.3 & 245 & 96.1 & 0.062 \\
\hline G & 1 & 0.7 & 10 & 3.9 & \\
\hline
\end{tabular}

Table VIII. Genotype frequencies in the study group according to age

\begin{tabular}{|c|c|c|c|c|c|}
\hline \multirow[t]{3}{*}{ Genotypes } & \multicolumn{4}{|c|}{ Study group } & \multirow[t]{3}{*}{$P$-value } \\
\hline & \multicolumn{2}{|c|}{ Nonagenarians } & \multicolumn{2}{|c|}{ Centenarians } & \\
\hline & $N$ & $N \%$ & $N$ & $N \%$ & \\
\hline \multicolumn{6}{|c|}{ TERT rs2736098: } \\
\hline AA & 23 & 9.6 & 0 & 0.0 & 0.164 \\
\hline GA & 99 & 41.3 & 5 & 29.4 & \\
\hline GG & 118 & 49.2 & 12 & 70.6 & \\
\hline \multicolumn{6}{|c|}{ IGFBP3 rs2854744: } \\
\hline AA & 70 & 29.5 & 7 & 41.2 & 0.597 \\
\hline$A C$ & 120 & 50.6 & 7 & 41.2 & \\
\hline $\mathrm{CC}$ & 47 & 19.8 & 3 & 17.6 & \\
\hline \multicolumn{6}{|c|}{ FOXO3A rs13217795: } \\
\hline $\mathrm{CC}$ & 30 & 12.6 & 3 & 17.6 & 0.014 \\
\hline CT & 110 & 46.0 & 13 & 76.5 & \\
\hline TT & 99 & 41.4 & 1 & 5.9 & \\
\hline \multicolumn{6}{|c|}{ FOXO3A rs2764264: } \\
\hline TT & 103 & 43.1 & 1 & 5.9 & 0.010 \\
\hline $\mathrm{CT}$ & 127 & 53.1 & 15 & 88.2 & \\
\hline $\mathrm{CC}$ & 9 & 3.8 & 1 & 5.9 & \\
\hline \multicolumn{6}{|c|}{ ADIPOQ rs2241766: } \\
\hline TT & 163 & 68.5 & 13 & 76.5 & 0.894 \\
\hline TG & 65 & 27.3 & 4 & 23.5 & \\
\hline$\overline{G G}$ & 10 & 4.2 & 0 & 0.0 & \\
\hline
\end{tabular}


V. Kolovou, H. Bilianou, V. Giannakopoulou, P. Kalogeropoulos, C. Mihas, M. Kouris, D.V. Cokkinos, M. Boutsikou, I. Hoursalas, S. Mavrogeni, N. Katsiki, G. Kolovou

Table IX. Allele frequencies in the study group according to age

\begin{tabular}{|c|c|c|c|c|c|}
\hline \multirow[t]{3}{*}{ Alleles } & \multicolumn{4}{|c|}{ Study group } & \multirow[t]{3}{*}{$P$-value } \\
\hline & \multicolumn{2}{|c|}{ Nonagenarians } & \multicolumn{2}{|c|}{ Centenarians } & \\
\hline & $N$ & $N \%$ & $N$ & $N \%$ & \\
\hline \multicolumn{6}{|c|}{ TERT rs2736095: } \\
\hline$A$ & 145 & 30.2 & 5 & 14.7 & 0.055 \\
\hline G & 335 & 69.8 & 29 & 85.3 & \\
\hline \multicolumn{6}{|c|}{ IGFBP3 rs2854744: } \\
\hline A & 260 & 54.9 & 21 & 61.8 & 0.434 \\
\hline $\mathrm{C}$ & 214 & 45.1 & 13 & 38.2 & \\
\hline \multicolumn{6}{|c|}{ FOXO3A rs13217795: } \\
\hline $\mathrm{C}$ & 170 & 35.6 & 19 & 55.9 & 0.018 \\
\hline $\mathrm{T}$ & 308 & 64.4 & 15 & 44.1 & \\
\hline \multicolumn{6}{|c|}{ FOXO3A rs2764264: } \\
\hline $\mathrm{T}$ & 333 & 69.7 & 17 & 50.0 & 0.017 \\
\hline $\mathrm{C}$ & 145 & 30.3 & 17 & 50.0 & \\
\hline \multicolumn{6}{|c|}{ ADIPOQ rs2241766: } \\
\hline $\mathrm{T}$ & 391 & 82.1 & 30 & 88.2 & 0.366 \\
\hline G & 85 & 17.9 & 4 & 11.8 & \\
\hline
\end{tabular}

polymorphisms with CVD and mortality in White $(n=8,907)$ and African-American participants $(n=3,022)$ in the Atherosclerosis Risk in Communities (ARIC) study with no history of CVD at baseline. They reported that 2 polymorphisms of the TERT gene (i.e. rs2853668 and rs2736122) were associated with CVD events (i.e. CHD and stroke) in African-Americans but not in Whites, suggesting inter-individual variation [18]. No associations with mortality were found in either racial group. However, Liu et al. [20] and Bressler et al. [18] evaluated different TERT gene polymorphisms from the one in our present study. The polymorphism evaluated by us (i.e. rs2736098A) has been associated with an increased risk of cancer as reported in a recent meta-analysis by Li et al. [19]; this association was more significant in Asians [19].

Roszkowska-Gancarz et al. found that serum adiponectin concentrations in female centenarians may be related to extreme longevity [21] and that adiponectin levels are modified by $A D I P O Q$ gene polymorphism. Khabour et al. [22] found no difference between $A D I P O Q$ gene polymorphisms (rs266729, rs2241766 and rs1501299) and longevity phenotype in a Jordanian population. Guzman-Ornelas et al. [23] evaluated the same gene polymorphism (rs2241766) as the one we studied, and did not observe any relationship between this polymorphism and adiponectin levels in Mex-
ican-Mestizo individuals. In our study, we also found no difference in ADIPOQ; rs2241766 gene polymorphism frequency between the 2 studied groups. In contrast, Atzmon et al. [24] reported that over-representation of 2 common variants in the ADIPOQ gene (rs17300539 and a single base pair insertion/deletion polymorphism 2019 bp downstream of the ATG start codon in the 3' untranslated region called as SNP+2019) may promote increased lifespan through the regulation of adiponectin production and/or secretion. With regard to CVD, which may shorten human life span, Kanu et al. [25] reported that variations in the $A D I P O Q$ gene may either protect against CHD (i.e. rs2082940T allele) or be associated with CHD risk (i.e. rs3774261G allele) in a Northeast Han Chinese population $(n=1514)$. Furthermore, a recent meta-analysis found no association between the T45G polymorphism of the adiponectin gene and nonalcoholic fatty liver disease (NAFLD) [26]. It should be noted that NAFLD and its advanced form (i.e. nonalcoholic steatohepatitis, $\mathrm{NASH}$ ) have been linked to increased liver and CVD morbidity and mortality [27, 28].

In a genome-wide association study of 10,280 middle-aged and older individuals, Kaplan et al. [29] confirmed a known association of the IGFBP3 gene with IGFBP-3 levels and a borderline significant association between IGF-I concentration and 
FOXO3; rs2153960 and longevity. Similarly, He et al. [30-32] reported an association of IGFBP3; rs11977526 gene polymorphism with longevity phenotype in a Chinese cohort, which was different from our studied polymorphism (rs2854744). Deal et al. [31] found in 478 men from the Physicians' Health Study that the A allele had higher promoter activity at the -202 locus compared with the C allele of IGFBP3 gene polymorphism, which is consistent with the relationship observed between genotype and circulating IGFBP-3.

Willcox et al. [12] first observed the association of FOXO3A; rs2802292 gene polymorphisms with longevity in 213 male Americans of Japanese ancestry aged > 95 years old. This association was confirmed in Italian, American, Chinese and German populations [9-12].

Soerensen et al. [32] investigated fifteen FOXO3A gene polymorphisms in 1,088 oldest old Danes (age: 92-93) and found further evidence for the role of FOXO3A as a longevity candidate gene from younger ages to old age, but not during old age. In the same cohort, they also evaluated the association of the FOXO3A gene with aging-related phenotypes known to predict survival (i.e. cognitive function, self-reported health, hand grip strength and activity of daily living) in the oldest old and found that FOXO3A variations were related to bone fracture risk and activity of daily living [33]. Furthermore, Flachsbart et al. [10] studied 16 known FOXO3A SNPs in 1,762 German centenarians/nonagenarians and younger controls and observed that the allele and genotype frequencies for the nonagenarians were generally in the middle between those for the younger controls and for the centenarians, supporting the reported increase in allele and genotype frequencies with age. Furthermore, after correcting for multiple testing, some SNPS (rs3800231, rs9400239, and rs479744) remained significant, including rs13217795 and rs2764264, for men separately. Unfortunately, there is no overlap with our polymorphisms tested. With regard to men, we also found that the frequency of TT genotype of FOXO3A; rs2764264 was higher in the study group than the control group. Additionally, in the present study, we found that the $C$ allele of rs2764264 of the FOXO3A gene was significantly lower in the study group than the control group. Similarly, Flachsbart et al. [10] reported that no FOXO3A SNPS correlated with longevity in centenarians compared with controls except for rs2764264. In the present study, among the oldest old (i.e. nonagenarians and centenarians), we found that the T allele was significantly more frequent in nonagenarians than centenarians for both variants of the $\mathrm{FOXO} 3 \mathrm{~A}$ gene.

FOXO3A is part of the insulin/IGF-1 signaling pathway, one of the key candidate pathways of longevity [34], and regulates the expression of several genes involved in a broad range of biological processes such as apoptosis, cell cycle transition, DNA repair, oxidative stress, cell differentiation and glucose metabolism [35]. Several animal studies have confirmed the positive role of the FOXO family in longevity. For example, lack of FOXO in Drosophila melanogaster increases sensitivity to oxidative stress [36], whereas its overexpression in Drosophila fat body was reported to reduce fecundity and increase lifespan in females (but not in males) [37]. FOXO3 knockout female mice exhibited early depletion of functional ovarian follicles, oocyte death and infertility [38]. Furthermore, B cell localization and development, Ig levels and hematopoietic stem cell maintenance were affected in FOXO3 knockout mice $[39,40]$. Limited studies in humans evaluated the relationship between FOXO3A gene polymorphisms and ageing-related phenotypes in the oldest old. Kuningas et al. [41] observed an increased risk of stroke and Pawlikowska et al. [42] found that rs4946935 was associated with death caused by cancer. Therefore, the FOXO3A gene may be considered as the second consistently confirmed longevity-associated gene in addition to the apolipoprotein E gene (APOE) according to current evidence in several study populations [9, 11, 12, 42-44].

Genetic studies on human longevity present a variety of limitations mainly due to the difficulty in enrolling a considerable number of oldest old and the non-existence of individuals born at the same time as centenarians but with different lifespan duration. Although there are data identifying some genes as related to longevity and ageing, more evidence is needed. In addition, epigenetics linked to diet or other environmental/lifestyle factors (such as smoking, physical activity and emotional stress) may play a role in longevity attainment [45-47].

The present study has the limitations and concerns of bias introduced by differences in characteristics of cases and controls due to its case-control study design. Furthermore, no environmental factors (e.g. smoking, exercise and others) were evaluated. There is only a small number of centenarians compared with nonagenarians, and the results might be exaggerated. However, our study has some strengths as the participants were carefully selected in accordance with race, age and family history, which were well documented.

In conclusion, there are differences in both studied FOXO3A gene polymorphisms according to survival status. Particularly, the individuals $>90$ years (i.e. the study group) had half of the $C$ alleles compared with younger individuals $<80$ years (i.e. the control group). Furthermore, the centenarians less frequently had the $\mathrm{T}$ allele of both FOXO3A gene polymorphisms compared with the nona- 
genarians. No differences were found between the 2 groups with regard to TERT, IGFBP3 and $A D I P O Q$ gene polymorphisms. Therefore, it seems that some polymorphisms may be significant in prolonging our lifespan. Understanding ageing at a molecular level could possibly help us in slowing this process and extend our lifespan. Nevertheless, confirmation in additional study populations is needed.

\section{Conflict of interest}

This study was conducted independently; no company or institution supported it financially. None of the authors have any conflict of interest to report with regard to this paper. $\mathrm{VK}, \mathrm{PK}, \mathrm{CM}, \mathrm{MK}$, DVC, MB, IH, SM have nothing to declare. DVC, HB and GK have given talks, attended conferences and participated in trials sponsored by Amgen, Angelini, MSD, Lilly, Vianex and Sanofi-Aventis. NK has given talks, attended conferences and participated in trials sponsored by Amgen, Angelini, Astra Zeneca, Boehringer Ingelheim, Galenica, MSD, Novartis, Novo Nordisk, Sanofi-Aventis and WinMedica.

\section{References}

1. Avery P, Barzilai N, Benetos A, et al. Ageing, longevity, exceptional longevity and related genetic and non-genetics markers: panel statement. Curr Vasc Pharmacol 2014; 12: 659-61.

2. vB Hjelmborg J, lachine I, Skytthe A, et al. Genetic influence on human lifespan and longevity. Hum Genet 2006; 119: 312321.

3. Kolovou G, Kolovou V, Vasiliadis I, et al. The frequency of 4 common gene polymorphisms in nonagenarians, centenarians, and average life span individuals. Angiology 2014; 65: 210-5.

4. Collins K, Mitchell JR. Telomerase in the human organism. Oncogene 2002; 21: 564-79.

5. Tzanetakou IP, Katsilambros NL, Benetos A, Mikhailidis DP, Perrea DN. "Is obesity linked to aging?": adipose tissue and the role of telomeres. Ageing Res Rev 2012; 11: 220-9.

6. Lin $C M$, Huang $Y L$, Lin ZY. Influence of gender on serum growth hormone, insulin-like growth factor-I and its binding protein-3 during aging. Yonsei Med J 2009; 50: 407-13.

7. Rajaram S, Baylink DJ, Mohan S. Insulin-like growth factor-binding proteins in serum and other biological fluids: regulation and functions. Endocr Rev 1997; 18: 801-31.

8. Su X, Colditz GA, Willett WC, et al. Genetic variation and circulating levels of IGF-I and IGFBP-3 in relation to risk of proliferative benign breast disease. Int J Cancer 2010; 126: $180-90$

9. Anselmi CV, Malovini A, Roncarati R, et al. Association of the FOXO3A locus with extreme longevity in a southern Italian centenarian study. Rejuvenation Res 2009; 12: 95-104.

10. Flachsbart F, Caliebe A, Kleindorp R, et al. Association of FOXO3A variation with human longevity confirmed in German centenarians. PNAS 2009; 106: 2700-5.
11. Li Y, Wang WJ, Cao H, et al. Genetic association of FOXO1A and FOXO3A with longevity trait in Han Chinese populations. Hum Mol Genet 2009; 18: 4897-904.

12. Willcox BJ, Donlon TA, He Q et al. FOXO3A genotype is strongly associated with human longevity. PNAS 2008, 105: 13987-92.

13. Buckbinder L, Talbott R, Velasco-Miguel S, et al. Induction of the growth inhibitor IGF- binding protein 3 by p53. Nature 1995; 377: 646-9.

14. Vionnet N, Hani EH, Dupont S, et al. Genome wide search for type 2 diabetes-susceptibility genes in French whites: evidence for a novel susceptibility locus for early-onset diabetes on chromosome 3q27-qter and independent replication of a type 2-diabetes locus on chromosome 1q21-q24. Am J Hum Genet 2000; 67: 1470-80.

15. NCI-NHGRI Working Group on Replication in Association Studies, Chanock SJ, Manolio T, Boehnke M, et al. Replicating genotype-phenotype associations. Nature 2007; 447: 655-60.

16. Declaration of Helsinki for Human Research of 1974 (last modified in 2000).

17. Valdes AM, Andrew T, Gardner JP, et al. Obesity, cigarette smoking, and telomere length in women. Lancet 2005; 366: 662-4.

18. Bressler J, Franceschini N, Demerath EW, Mosley TH, Folsom AR, Boerwinkle E. Sequence variation in telomerase reverse transcriptase (TERT) as a determinant of risk of cardiovascular disease: the Atherosclerosis Risk in Communities (ARIC) study. BMC Medical Genetics 2015; 16: 52.

19. Li C, Yin Z, Wu W, Li X, Zhou B. Genetic variants in TERT-CLPTM1L genetic region associated with several types of cancer: a meta-analysis. Gene 2013; 10: 390-9.

20. Liu L, Wang C, Lu X, et al. The MNS16A polymorphism in the TERT gene in peri-centenarians from the Han Chinese population. Sci China Life Sci 2014; 57: 1024-7.

21. Roszkowska-Gancarz M, Bartoszewicz Z, Polosak J, et al. Total and high molecular weight adiponectin and level-modifying polymorphisms of ADIPOQ in centenarians. Endokrynol Pol 2012; 63: 439-46.

22. Khabour OF, Mesmar FS, Alatoum MA, Gharaibeh MY, Alzoubi KH. Associations of polymorphisms in adiponectin and leptin genes with men's longevity. Aging Male 2010; 13: 188-93.

23. Guzman-Ornelas MO, Chavarria-Avila E, Munoz-Valle JF, et al. Association of ADIPOQ $+45 T>G$ polymorphism with body fat mass and blood levels of soluble adiponectin and inflammation markers in a Mexican-Mestizo population. Diabetes Metab Syndr Obes 2012; 5: 369-78.

24. Atzmon G, Pollin TI, Crandall J, et al. Adiponectin levels and genotype: a potential regulator of life span in humans. Gerontol A Biol Sci Med Sci 2008; 63: 447-53.

25. Kanu JS, Gu Y, Zhi S, et al. Single nucleotide polymorphism rs3774261 in the AdipoQ gene is associated with the risk of coronary heart disease (CHD) in Northeast Han Chinese population: a case-control study. Lipids in Health and Disease 2016; 15: 6 .

26. Zhang W, Zhu LQ, Huo XL, Qin J, Yuan GY. Association between adiponectin gene $\mathrm{T} 45 \mathrm{G}$ polymorphism and nonalcoholic fatty liver disease risk: a meta-analysis. Genet Mol Res 2016; 15: doi: 10.4238/gmr.15017190.

27. Katsiki N, Mikhailidis DP, Mantzoros CS. Non-alcoholic fatty liver disease and dyslipidemia: an update. Metabolism 2016; 65: 1109-23.

28. Athyros VG, Tziomalos K, Katsiki N, Doumas M, Karagiannis A, Mikhailidis DP. Cardiovascular risk across the histological spectrum and the clinical manifestations 
of non-alcoholic fatty liver disease: an update. World J Gastroenterol 2015; 21: 6820-34.

29. Kaplan RC, Petersen AK, Chen MH, et al. A genome-wide association study identifies novel loci associated with circulating IGF-I and IGFBP-3. Hum Mol Genet 2011; 20: 1241-51.

30. He YH, Lu X, Yang LQ, Xu LY, Kong QP. Association of the insulin-like growth factor binding protein 3 (IGFBP-3) polymorphism with longevity in Chinese nonagenarians and centenarians. Aging (Albany NY) 2014; 6: 944-56.

31. Deal C, Ma J, Wilkin F, et al. Novel promoter polymorphism in insulin-like growth factor-binding protein-3: correlation with serum levels and interaction with known regulators. J Clin Endocrinol Metab 2001; 86: 1274-80.

32. Soerensen M, Dato S, Christensen K, et al. Replication of an association of variation in the FOXO3A gene with human longevity using both case-control and longitudinal data. Aging Cell 2010; 9: 1010-7.

33. Soerensen M, Nygaard M, Dato $S$, et al. Association study of FOXO3A SNPs and aging phenotypes in Danish oldest-old individuals. Aging Cell 2015; 14: 60-6.

34. Christensen K, Johnson TE, Vaupel JW. The quest for genetic determinants of human longevity: challenges and insights. Nat Rev Genet 2006; 7: 436-48.

35. Huang $\mathrm{H}$, Tindall DJ. Dynamic FoxO transcription factors. J Cell Sci 2007; 120: 2479-87.

36. Junger MA, Rintelen F, Stocker $\mathrm{H}$, et al. The Drosophila forkhead transcription factor FOXO mediates the reduction in cell number associated with reduced insulin signaling. J Biol 2003; 2: 20.

37. Giannakou ME, Goss M, Junger MA, Hafen E, Leevers SJ, Partridge L. Long-lived Drosophila with overexpressed dFOXO in adult fat body. Science 2004; 305: 361.

38. Castrillon DH, Miao L, Kollipara R, Horner JW, Depinho RA. Suppression of ovarian follicle activation in mice by the transcription factor Foxo3a. Science 2003; 301: 215-8.

39. Hinman RM, Nichols WA, Diaz TM, Gallardo TD, CastrilIon DH, Satterthwaite AB. Foxo3-/- mice demonstrate reduced numbers of pre- $B$ and recirculating $B$ cells but normal splenic $B$ cell sub-population distribution. Int Immunol 2009; 21: 831-42.

40. Miyamoto K, Araki KY, Naka K, et al. Foxo3a is essential for maintenance of the hematopoietic stem cell pool. Cell Stem Cell 2007; 1: 101-12.

41. Kuningas M, MägiR, Westendorp RG, Slagboom PE, Remm M, van Heemst D. Haplotypes in the human Foxola and Foxo3a genes: impact on disease and mortality at old age. Eur J Hum Genet 2007; 15: 294-301.

42. Pawlikowska L, Hu D, Huntsman S, et al. Study of Osteoporotic Fractures. Association of common genetic variation in the insulin/IGF1 signaling pathway with human longevity. Aging Cell 2009; 8: 460-72.

43. Bao JM, Song XL, Hong YQ, et al. Association between FOXO3A gene polymorphisms and human longevity: a meta-analysis. Asian J Androl 2014; 16: 446-52.

44. Broer L, Buchman AS, Deelen J, et al. GWAS of longevity in CHARGE consortium confirms APOE and $\mathrm{FOXO} 3$ candidacy. Gerontol A Biol Sci Med Sci 2015; 70: 110-8.

45. Kolovou G, Kolovou V, Vasiliadis I, Wierzbicki AS, Mikhailidis DP. Ideal lipid profile and genes for an extended life span. Curr Opin Cardiol 2011; 26: 348-55.

46. Kolovou G, Stamatelatou M, Anagnostopoulou K, et al. Cholesteryl ester transfer protein gene polymorphisms and longevity syndrome. Open Cardiovasc Med J 2010; 4: 14-9.

47. Kolovou GD, Kolovou V, Mavrogeni S. We are ageing. Biomed Res Int 2014; 2014: 80830. 